\title{
Libraries and museums in the flat world: Are they becoming virtual destinations? ${ }^{\grave{s}}$
}

\author{
Yaşar Tonta \\ Department of Information Management, Hacettepe University, 06800 Beytepe, Ankara, Turkey
}

\section{A R T I C L E I N F O}

\section{Article history:}

Available online 26 June 2008

\section{Keywords:}

Libraries as virtual destinations

Museums as virtual destinations

Digitization of cultural heritage resources

"Inside out" digital cultural repositories

\begin{abstract}
A B S T R A C T
In his recent book, "The World is Flat", Thomas L. Friedman reviews the impact of networks on globalization. The emergence of the Internet, web browsers, computer applications talking to each other through the Internet, and the open source software, among others, made the world flatter and created an opportunity for individuals to collaborate and compete globally. Friedman predicts that "connecting all the knowledge centers on the planet together into a single global network... could usher in an amazing era of prosperity and innovation". Networking also is changing the ways by which libraries and museums provide access to information sources and services. In the flat world, libraries and museums are no longer a physical "place" only: they are becoming "virtual destinations". This paper discusses the implications of this transformation for the digitization and preservation of, and access to, cultural heritage resources.
\end{abstract}

(C) 2008 Elsevier Inc. All rights reserved.

\section{Introduction}

Are libraries ${ }^{1}$ becoming "virtual destinations"? The direct and short answer to this question would be a firm "Yes". What follows is a brief discussion of the recent transformation of physical libraries into virtual destinations.

As is well known, collection management policies of libraries were mainly shaped by in-house use of materials in the past. Users were primarily limited to those who can physically travel to the library building. They would come to the library, consult the card catalog, and, if available, get access to the books they wanted. Online catalogs replaced card catalogs in 1980s. They became available for remote searching through telnet and, later, through the World Wide Web. In 1990s, users were no longer required to travel to the library building to consult the catalog. This was the first sign of libraries becoming virtual destinations.

Later, electronic journals (e-journals) and electronic books (e-books) became available through publishers' or aggregators' web sites. Libraries provided remote access to the full-texts of journal articles and books by licensing them from publishers and aggregators. The emergence of e-journals and the initiatives of Open Access and Google Book Search have further accelerated the process of transformation from physical libraries to virtual libraries. While a library of the past used to provide access to its information resources through a stand-alone user interface, a virtual library opened its catalog to the users of other libraries by means of Z39.50 meta-search engines that recognize common resource description standards. Access to the full-texts of those resources by remote users continued to be an issue.

Library users on the other hand demanded libraries to provide services similar to those of Amazon and Google ("Amazoogle") [6]. Libraries began to move not only the descriptions but also the full-texts of their collections to the Web and share them with users of other institutions via the Metadata Harvesting Protocol of the Open Archives Initiative (OAI-MHP) and the OpenURL

\footnotetext{
is Earlier versions of this paper appeared in [30,31].

E-mail address: tonta@hacettepe.edu.tr.

1 The term "libraries" is used loosely in this paper to encompass libraries as well as other cultural heritage institutions such as archives that primarily preserve, and provide access to, graphic records (manuscripts as well as printed books) of humanity.
} 
standard. Moreover, they opened their collections to the spiders of commercial search engines such as Google so that information sources owned by libraries can be discovered and used by more people including their own users. Such initiatives as OCLC's Open WorldCat Libraries, Google Scholar, Google Book Search and Yahoo! Subscriptions are increasingly transforming libraries into virtual destinations.

\section{Where's the library?}

It can be argued that that just because some information sources are accessible through the Internet does not make libraries virtual destinations. The physical library still performs important functions as a place to gather, to learn, and to get free access to the Internet. Metaphors such as "Library is the heart/brain of the university" emphasize the physical library as a "place". The late American author and historian Shelby Foote defined the university "as a bunch of buildings gathered around the library". Although each campus may have a university library building at its center, it is getting more difficult to identify where exactly the library is on campus. Kohl [15] suggests that the library can no longer be characterized by its building only: the contents and services offered by the library are more important. Yet, the contents of a library (e.g., e-journals, e-books, and open access government publications) are increasingly becoming available outside the library building. Users can get networked access to those sources from publishers' web sites. Kohl [15] emphasizes the fact that this transformation is not limited with the collections: functions such as reference services and user training are being redefined outside the "library-as-a-place" metaphor.

Even though the emphasis on library buildings may still be dominant across campuses, such metaphors do not change the fact that libraries are increasingly becoming virtual destinations. For example, statistics gathered by the Association of Research Libraries (ARL) from 123 large university libraries in the United States clearly show this trend. Member libraries experienced a 16\% decrease in the number of borrowed books in recent years, $29 \%$ decrease in reference questions, and $49 \%$ decrease in in-library use of materials [18], p. 10). While the University of California Libraries loaned more than 6 million books in the 2000-2001 academic year, this figure was almost halved in the following 4 years. ${ }^{2}$ Similar trends have been observed in the university libraries worldwide.

Decreases in numbers of users physically visiting libraries, asking face-to-face reference questions, or attending user training sessions should not be interpreted to mean that the overall use of library collections has also decreased correspondingly. On the contrary, the overall use has increased tremendously since library collections became, at least in part, accessible through the Web. Users were no longer required to make a visit to the library to make use of collections and services. They viewed and downloaded more articles and books simply by visiting the library from afar as a virtual destination using their desktops, laptops or even mobile phones through wired/wireless connections.

Libraries seeing this trend as an opportunity have increased the number of licensed databases, e-journal and e-book packages that are available for remote use. Similarly, they developed electronic document delivery, electronic reference and electronic reserve services for remote users. Members of ARL spend, on the average, one third of their acquisition budgets for electronic information sources. Some spend even more (e.g., more than 50\%). Some 270 million dollars were expended by 100 ARL members to provide online access to electronic journals in the 2003-2004 academic year ([17], p. 20).

\section{The rise of the library as a virtual "place"}

Some librarians may be worried that users visit libraries less frequently. Yet, there is no reason to believe that users who are able to get networked access to information sources and services would complain much about that. It is probably not very realistic to think that users would complain about libraries being virtual destinations, especially if they can get access to collections and services on a 7/24 basis. On the contrary, they get "instant satisfaction". As is the case in the online banking industry, it is much cheaper to use information sources and services remotely than in-house, face-to-face use in the library. Limited resources of libraries do not get bogged down. Think about the queues in front of reference desks, online catalog terminals, and so on. Furthermore, instant satisfaction comes from users' being able to renew their books borrowed from the library through their mobile phones or to conduct online searches on library databases and to download, say, their favorite music on to their Blackberries for instant playing. In short, these developments should not necessarily be interpreted as something to worry about.

Perhaps one might think that it is neither appropriate nor fair to compare libraries as non-profit institutions with commercial banks. As we emphasized at the beginning, library as a place performs crucial societal functions. The transformation of libraries into virtual destinations does not lessen their value to the society, though, just as banks providing round the clock access to customers' accounts and banking services do not get less good treatment. Users would value libraries even more if sources and services being accessed remotely are as good as those provided in-house, especially during off hours. The traditional "one sourceone user" approach is not valid for networked access to library resources: more than one user can get access to the same e-journal article simultaneously at any given time and download it.

The availability of remote access decreases the number of users physically visiting libraries and the number of reference questions [5]. Users who do not physically visit libraries are now on the network, of course. Libraries are therefore in the process of transferring some of their services to the web environment (e.g., digital reference services) so that users can use online reserve collections, ask reference questions via electronic mail, take a virtual tour of the library facilities and collections, and review

\footnotetext{
2 See University of California Library Statistics. http://www.slp.ucop.edu/stats/.
} 
tutorials in their own pace from their homes, dorms or labs without putting up with lines. Instead of worrying about libraries becoming virtual destinations, librarians should strive to transfer their sources and services into the network environment as much as possible. "Our users expect simplicity and immediate reward and Amazon, Google, and iTunes are the standards against which we [libraries] are judged. Our current systems pale beside them" ([32], p. 7).

As emphasized in a recent report prepared for the Library of Congress, "[t]oday's research library... reflects only a small portion of the expanding universe of scholarly information. The library is not the first or only stop for many information seekers. Search engines are the favorite place to begin a search ..." ([3], p. 26). Through search engines such as Google or Yahoo!, users can conveniently get access to several online sources and services provided by institutions other than libraries. If satisfied, they may not even want to visit the library web sites as virtual destinations any more, let alone visit the physical library buildings. Developments in the process of transformation of libraries and museums into virtual destinations are discussed in more detail below.

\section{Libraries in the flat world}

Thomas L. Friedman, a New York Times columnist, published a book last year with the catchy title of The World is Flat: A Brief History of the Globalized World in the Twenty-First Century [11]. In his book Friedman discusses convincingly how fiber optic cables, networks, satellites and the Internet flattened the world and made it possible for people as well as companies from different continents to communicate, cooperate and compete globally. What he means by "flattening of the world" is as follows: "...we are now connecting all the knowledge centers on the planet together into a single global network, which - if politics and terrorism do not get in the way - could usher in an amazing era of prosperity and innovation" ([11], p.8).

Friedman reviews the impact of 10 "flatteners" that gave way to globalization. The most important flatteners were the outcome of recent developments in the information world. The first flattener was the availability of Microsoft Windows operating system for personal computers which offered a universal graphical user interface "to look at the world through". The second one was the development of the web browser Netscape Navigator in 1995 that made the world flatter, enabling users to view web pages no matter where the page is located. The third one was the development of the workflow software and standards that enabled different applications running on different computers to talk to one another. These three flatteners together made it possible for individuals and groups to make use of the remaining seven flatteners (open sourcing, outsourcing, offshoring, supply-chaining, insourcing, informing, and the "steroids") ([11], p. 48-172). ${ }^{3}$

As Friedman emphasizes, such flatteners as the World Wide Web, Netscape Navigator and the open (free) source software enable users to get networked access to information centers on a global scale and share information sources regardless of where they are located. In other words, the "death of distance" in the flat world also facilitates the transformation of libraries into virtual destinations. For instance, users looking for Friedman's book in the University of California Libraries union catalog Melvyl (melvyl.cdlib.org) discover that, in addition to 13 printed copies and CD's of the book available in different campus libraries scattered all over the State of California, the full-text of Friedman's book is available online. Even though libraries own printed copies of the book to borrow, University of California Libraries suddenly become a virtual destination for many users entitled to download the full-text of Friedman's book remotely through the network. Those users do not have to visit the campus libraries for Friedman's book any more. Nor do they have to deal with renewing or returning the book.

On the other hand, the distance is not dead, at least not yet, for users who cannot get access to the full-text of Friedman's book through their library web sites. Libraries not offering online access to the book in question are not virtual destinations yet from the users' point of view. Yet, library catalogs should provide information about Friedman's book even if it is not owned locally. For instance, rather than the library catalog reporting back to the user that the book is not in the local collection, its bibliographic information can easily be obtained from Amazon or Google, thereby giving the user a chance to order it. Better, the library catalog might offer several options to the user ("we don't have it yet but we can buy its electronic copy immediately for you from online book stores, if available,"; "we can order its printed copy for you"; "we can get it for you via interlibrary loan"; "we don't have the book yet but here are some reviews, the full-texts of which can be accessed from our e-journal collection"). Online catalogs providing such useful help to their users are scarce.

Most libraries do not currently act on the basis of the requirements of the "flat world". Rather than informing the user of the availability of several choices by simply consulting networked sources automatically, library catalogs simply report back to the user "zero result". On the other hand, Amazon provides detailed information about the book in question ranging from the book's table of contents to searching "Inside the Book" (and reading a certain part of it online), from reviews by the users who bought the book earlier to a concordance and text statistics. Should the user decide to buy the online copy of the book, s/he can immediately download the full-text and start reading. Similarly, users searching for Friedman's book on Google can get access to several articles and reviews about the book including those published in the New York Times, New York Review of Books and Wired, publisher's (Farrar, Straus and Giroux) introduction, a Wikipedia article, author's web site and information about author's other books. Users can even view the video of an interview with the author from the NTVMSNBC television's web site [29].

\footnotetext{
${ }^{3}$ We do not aim to discuss the impact of all flatteners or summarize Friedman's book, which is a thought-provoking reading. The book provides an opportunity to review the recent developments from Friedman's liberal viewpoint and to reflect on their impact on the information world.
} 


\section{Amazoogle}

Amazon is the largest online bookseller of the world. Google search engine answers some one billion queries every day. Google and Amazon are among the most frequently visited virtual destinations. Compared with the detailed information about books that these two virtual destinations offer, library catalogs provide next to nothing. Very few library catalogs submit unsuccessful searches automatically to Amazon or Google to inform users [6]. If libraries fail to offer as much information about books and other materials as Amazon, users may no longer consider libraries as virtual destinations. As library catalogs produce "zero results" with no alternative choices, users may give up visiting library web sites forever, making them obsolete.

Libraries have to work hard to "deserve" being virtual destinations. Most libraries in the past operated on the basis of "take it, or leave it" approach. Users had to visit the library building in order to get access to sources and services because there was no other alternative. Things have changed quite dramatically, though, with the emergence of the World Wide Web and the availability of a wide variety of information sources through the Internet. Libraries are now challenged by other information providers that offer round the clock networked information services. Libraries are no longer the only choice in the flat world. They are challenged by many non-profit as well as commercial entities providing web-based information services. Library catalogs therefore need to be revamped in the new resource discovery environment [8]. Otherwise, users can easily "take their business elsewhere" and switch to competitor's services. Calhoun ([3], p. 19) makes a number of suggestions to improve the users' experience with library catalogs. Among them are:

- Enrich the catalog with services and data;

- Federate discovery and delivery of books, journals, and journal articles;

- Link the user to full-text whenever possible;

- For items that cannot be delivered instantly, offer a range of unmediated, quick delivery options;

- Push library metadata and links out to course Web pages and portals;

- Take advantage of e-commerce functions to serve non-members of the library community.

Dempsey [6] calls this era as the "Amazoogle" age and emphasizes that libraries should provide networked access to information sources and services as much as Amazon or Google does. The Amazoogle approach provides both centralization and distribution from the users' point of view. For example, users can perform a single search on the Open WorldCat catalog, developed by OCLC in cooperation with Google, and locate which OCLC member libraries throughout the world own the requested source(s). The prerequisite for this is that libraries need to move their records to the Open WorldCat catalog so that their metadata will be exposed to major search engines. The Google and Yahoo! search engines also list the records of OCLC member libraries through what is called the "Find in a Library" feature. Therefore, one way to make millions of Google and Yahoo! users aware of what your library can offer is to add your records to OCLC's Open WorldCat catalog.

On the other hand, the Amazoogle approach requires not only metadata but also the full-texts of information sources to be available through the World Wide Web. The OAI-PMH ${ }^{4}$ compatible metadata of libraries can be harvested by the crawlers of search

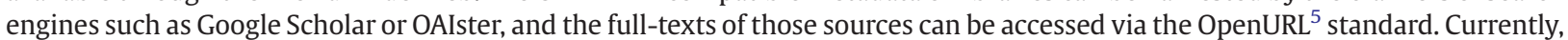
more than 100 libraries opened their collections and databases to the crawlers of Google Scholar (scholar.google.com), thereby opening their resources to potentially a much wider user group [29]. Similarly, Google's Book Search (books.google.com), developed in cooperation with publishers as well as some large US libraries, offers full-text search on books.

It is exciting to think of all the knowledge centers in the world connected to the Internet, as Friedman emphasized. Yet, apart from some innovative applications, not all libraries are connected into, nor are their contents accessible through, a global network. Moreover, various services offered by libraries also need to be accessible through the network. With reference to Friedman's "flat world", Dempsey [7] describes the transfer of library resources and services to the World Wide Web as "flattening the library and turning it inside out".

\section{Inside out Library}

Lorcan Dempsey coined the term "inside out library". What he means by "turning libraries inside out" is that "the library needs to be where the user is - on the network" [7]. He points out that the network has changed the information seeking and learning behaviors of users [9]. In the flat world users consult the network first when they do research. Dempsey maintains that the impact of networking technology on research and learning will be more profound than its impact on library systems and services. As users are increasingly on the network, libraries should develop networked services to support users' workflows ${ }^{6}$ and integrate contents and services to users' network environment. To do that, libraries should take what is available "inside" the library buildings (resource environment, including related services) "out" to where the users are -the network (user environments). The resource environment includes, among others, library catalogs, abstract and index databases, digitized collections, full-texts of licensed information sources, institutional archives, virtual reference, electronic reserve and electronic document delivery services. The

\footnotetext{
4 For the definition of the Protocol for Metadata Harvesting of Open Archives Initiative, see [24].

5 For the OpenURL standard, see [23] for more information on OpenURL and its applications, see [33,1].

6 In addition to user "workflow", Dempsey [7] mentions user "learnflow", "commuteflow", "lifeflow", and "research flow", each of which requires users to get access to information sources and services.
} 
user environments also include a wide variety of resources: personal collections, personal digital assistants (PDAs), learning management systems, campus portals, course materials, textbooks, lab books, reading lists, and so on [7]. Users need library resources and services in their daily workflows to complete a number of tasks ranging from preparing reading lists and creating personal collections to getting access to the full-texts of resources and asking reference questions. The traditional approach to satisfy users' needs was to have the user come to the library whereas the approach preferred in the flat world is to have the library to become an integral part of the users' environments on the network to support their workflows. This is exactly what "inside out library" is all about.

It is certainly not easy to materialize the "inside out library". For a successful "flattening", the library has to be effective systemwide by consolidating data, services and innovations in an organization. The library should be able to work with different platforms in each user envrionment and combine these platforms effectively. User platforms range from sophisticated computer/mobile phone hardware/software (e.g., PDAs or Blackberries) to learning management systems (e.g., WebCT, Blackboard) or personal reference managers (e.g., EndNote) that run on this hardware and infrastructure. The value of libraries will be measured by how effectively they become part of users' workflows [7].

Libraries as virtual destinations can be regarded as a crucial component of the "inside out library" concept. The existing model of each library creating its own "vertical silos" cannot be sustained. In order for libraries to transform themselves into virtual destinations, they need to "overcome fragmentation caused by vertical silos" [6]. This fragmentation can be overcome by developing deep cooperation not only between the library and the organization in which it operates but also between other organizations and third-party information providers.

Libraries as virtual destinations need to be "one stop shops", not "one shop stops". For this, they need to enrich their network accessible resources and services and create OAI-PMH compatible metadata that can be harvested by the crawlers of search engines such as Google Scholar or OAIster. They should offer access not only to their own sources and services but also function as a gateway to get access to licensed databases, third-party information services, and electronic document delivery services. The existing rather slow processing workflow of library materials should be changed from '“Acquire-Catalog-Put on Shelf' to 'AcquirePut on Shelf with existing metadata-Begin ongoing metadata enhancement process through automated query of metadata sources"” ([32], p. 26). Users would then be hooked to the library web sites as virtual destinations rather than shying away to competitive services. Libraries that cannot function as efficient as competition are likely to be bypassed and ignored in the flat world.

\section{Museums in the flat world}

Libraries are important cultural heritage institutions in the world. So are museums. What is said above for libraries is valid to a great extent for museums as well (e.g., "inside out museums", “museums as virtual destinations"). Museums, too, are faced with several challenges in the flat world. The increasing amount of content which needs storage areas, fragile objects, geographically disperse museum buildings, travel costs, and natural hazards are among them [4].

Museums wish to make users aware of what they own in the sense that libraries do by turning their insides out. Using OAI-PMH protocol mentioned earlier, several museums made their metadata of cultural heritage information resources harvestable by search engines [28]. Virtual museums "allow the user to experience the content of the museum virtually, i.e., in a place or time physically separate from the museum...by digitizing the content of the museum." This will allow the user "to view or study any part of the museum content at any time, from any place [12]. The Virtual Museum of Canada (www.virtualmuseum.ca) and the Online Archive of California (www.oac.cdlib.org) can be given as examples of virtual museums offering hundreds of thousands of images and interactive games, and hosting virtual exhibitions.

Digitization poses more questions for museums than it does for libraries and archives. While libraries preserve primarily the printed and graphic materials for future generations, museums collect 2D and 3D objects with scientific, artistic, architectural and cultural value. Scientific and cultural heritage materials preserved by libraries usually have more than one copy distributed worldwide through different libraries. Yet, museums usually deal with unique objects including 3D ones (e.g., pictures, sculptures, installations, and so on). They host not only individual museum pieces but also one-off exhibitions which may never be displayed again. There are also archeological sites, buildings, crafts and customs that need to be preserved as part of cultural heritage.

How could museums preserve such exhibitions, sites and artifacts? Hemminger, Bolas and Schiff [12] developed a methodology to capture "a record of an exhibit for archival purposes and for communication between curators, and for the design of virtual (never physically implemented) exhibits and pieces based on actual pieces and settings". Digitization of the exhibition is one way to do that. Even though the objects may not be preserved, a digital record of the exhibition can at least be preserved. This record can contain the digitized copies of 2D and 3D objects placed on the museum walls or floors.

Digitizing 2D and 3D objects and distributing them over the network is a more challenging endeavor. Think of a sculpture, say, Michelangelo's David. Digitizing its 3D representation takes about 500GB storage space and requires special software to view [12]. Supposing that all the copyright and distribution issues are resolved, it is currently difficult with limited bandwidth to deposit its digital copy and make it available over the network. Nonetheless, some encouraging digitization initiatives have been carried out. The web site of the Digital Archive Network for Anthropology and World Heritage (dana-wh.net) is "dedicated to the access, presentation, and preservation of material objects that represent human cultural and biological heritage worldwide." It is a network of a distributed, interoperable databases including not only descriptions but also 2D images of artifacts and fossils as well as 3D models thereof. "The 3D models are digital surrogates of actual specimens that can be manipulated and viewed from all 
angles, and are sufficiently precise to allow for a wide range of detailed measurements and analyses." Special software (Java3D) is needed to view 3D models of fossils and artifacts. ${ }^{7}$

Museum objects have two distinct types of users: general public and the researchers. The digitization requirements are quite different for the two types of users. While general public may be satisfied with a digital replica of a certain picture or sculpture, a researcher may wish to review it more closely, measure it, be able to view it from different angles, and so on. Lynch [20] points out that those who digitize the cultural heritage objects (e.g., researchers) usually have very little contact with those who use them for educational purposes (e.g., curators, museologists, etc.).

\section{Preservation of, and access to, the cultural heritage in the flat world}

Intellectual and artistic works, performances, and other creative productions of human beings - which can be defined as culture - get forgotten as time passes, unless they are recorded. Recorded objects have longer lives but they "inevitably decay" [19]. As Clark et al. [4] emphasizes, "[a]ccess to, and preservation of, the physical remains of human cultural and biological heritage are essential for an informed society." As a society we are "becoming increasingly dependent on digital artifacts to represent our cultural and artistic heritage" [26].

As the examples given earlier show, information and communication technologies (ICT) along with distributed databases provided an opportunity to open up the contents of libraries, archives and museums containing cultural heritage materials. Several nations as well as non-profit and for-profit institutions invested considerable amount of money to provide access to such repositories through the Web. Zorich [34] reviewed the issues in relation to the sustainability of digitial cultural heritage initiatives in the United States. The US Congress set aside some 100 million dollars in the year 2000 and designated the Library of Congress to develop a program to preserve digital information for future generations. The US-based National Initiative for Networked Cultural Heritage (NINCH) produced a "Guide to Good Practice in the Digital Representation and Management of Cultural Heritage Materials". 8 In 2003, UNESCO adopted a charter on the preservation of digital heritage ([10], p. 16-17).

\section{9. "Born digital"}

Preserving "born digital" scientific and cultural heritage materials is also a challenge. A study conducted a few years ago by two professors at the University of California at Berkeley estimated that some 5 exabytes ${ }^{9}$ (approximately $10^{18}$ bytes) of new information was produced in 2002. An overwhelming percentage (92\%) of this new information was stored on magnetic media. In a different study carried out by IDC, the "sizing of the digital universe-information that is either created or captured in digital form and then replicated in 2006" was estimated as 161 exabytes and a six-fold growth was forecast in 4 years, thereby bringing the total close to 1000 exabytes by the year 2010 ([13], p. 3). This incredible growth "raises the question as to whether it possible or worthwhile to preserve it all", even digitally, ${ }^{10}$ not to mention "who decides and who is responsible for preserving what and in what way?" ([10], p. 15).

The financial, organizational, technical and legal challenges that we mentioned earlier for the digitization of traditional materials are valid for the preservation of digital materials as well. For instance, "the real costs of long-term preservation of digital information are not clear" ([10], p. 18). Technically, born-digital cultural heritage objects are dynamic and intelligent, which requires more sophisticated preservation methods to accommodate changes introduced later to the objects ([10], p. 19). Since the preservation of born-digital objects depends on copying and migration, issues of intellectual property rights (IPR) (e.g., orphan works) need to be tackled ([10], p. 19).

Preservation of digitial information is a challenging task and it has been discussed in the literature for more than a decade along with its implications for the preservation of cultural heritage objects [25,27]. While it is easier to copy, distribute, process, revise, and improve born-digital objects, the relatively short life of most digital objects has made the preservation issue much more difficult than that of traditional ones. Digital artifacts have more to offer than traditional ones (e.g., multimedia components, interactivity, continuously updated links to other digital artifacts, and so on). Yet, the media on which digital artifacts are recorded as well as the software that runs the media can become obsolete in a short period of time, thereby making information inaccessible [26]. Rothenberg [26] refers to this dilemma as: "Digital information lasts forever - or 5 years, whichever comes first".

Museums, for example, deal not only with the digitization of cultural objects that reflect the past and make them available over the network, but also they have to deal with the digitization of cultural objects that are "born digital" that reflect the present, and to preserve them in perpetuity. Simulation software such as SimCity, virtual communities on the Web, and the World Wide Web itself can be given as examples. Copying, distributing and processing present-day born-digital cultural heritage "objects" is easier. Yet, preserving the born-digital cultural heritage, especially the intelligent objects such as dynamic web pages, can be difficult to preserve for future generations [20].

The Internet is currently the largest digital information "repository", containing exabytes of digital information ranging from simple textual documents to dynamic multimedia objects (e.g., pictures, sound files, movies, interactive games, 3D cultural

\footnotetext{
${ }^{7}$ The quotes come from the web site of DANA-WH (www.dana-wh.net). For a more detailed account of DANA, see [4].

${ }^{8}$ The Guide is available at http://www.ninch.org/programs/practice/.

${ }^{9}$ For more information on "exabyte" (EB), see http://en.wikipedia.org/wiki/Exabyte.

${ }^{10}$ For a thoughtful piece on the preservation of digital information, see [21].
} 
heritage objects). Kahle [14] attempted to "preserve the Internet" and developed the largest database in the world: the Internet Archive (the so called Wayback Machine) (www.archive.org). Built by Alexa Internet (www.alexa.com), the Internet Archive currently has 85 billion web pages indexed. ${ }^{11}$ Alexa Web Search Platform (websearch.alexa.com), released in December 2005, is "one of the largest and most complete repositories of Web content ever assembled". Alexa crawlers take snapshots of the Web regularly (daily for the popular Web content, every 2 months for a broad cross-section of the Web), each crawl consisting of 1.6 Terabytes of Web content spanning 4.5 billion pages from over 16 million sites. ${ }^{12}$ Alexa crawlers also record data regularly on the infamous "404 not found" pages, and it appears that terabytes of digital information get lost continuously [19].

Several methods have been suggested in the past to deal with the preservation of digital information, ranging from digital archeology to copying or migrating contents of the old media onto newer ones, from emulation to making multiple copies of the same object available on the distributed network (e.g., LOCKSS) to time capsule technologies. It is not clear yet if these methods would be a panacea to the long-term preservation of digital information. While new methods and techniques have been contemplated to tackle the long-term preservation issue, there is no doubt that some digital information including digital cultural heritage objects that are available through the Internet have to be preserved for posterity. Unless we develop satisfactory methods to solve the long-term preservation of all kinds of digital information, libraries, archives and museums cannot become truly virtual destinations and function in the flat world. The loss of precious digital information and digital cultural heritage resources may well trigger the beginning of what is called "the digital dark age" [16,2].

\section{Digitization of cultural heritage in Europe}

Europe has been active in the digitization of cultural heritage resources as they are seen as having "fundamental value for Europe's present and future". Digital cultural heritage resources comprise both digital substitutes of original objects and borndigital objects existing only in digital form. The European Union (EU) supported several digitization projects under its Information Society Technologies (IST) programme. DIGICULT (Digital Heritage and Cultural Content Programme of the European Commission) has been running as a thematic priority area in both the 5th and 6th Framework Programmes for Research and Technological Development (1998-2006). ${ }^{13}$ A number of European-wide projects such as CALIMERA (Cultural Applications: Local Institutions Mediating Electronic Resources), COINE (Cultural Objects in Networked Environments), ERPANET (Electronic Resources Preservation and Access Network), and NEDLIB (Networked European Digital Library) have been introduced to preserve cultural heritage and make it available over the network. More recently, the European Commission (EC) has announced its "i2010: Digital Libraries Initiative" with the motto of "Europe's Cultural and Scientific Heritage at a Click of a Mouse". "The essence of the initiative lies in the online availability of the heritage... [It] aims at making Europe's diverse cultural and scientific heritage...easier and more interesting to use online for work, leisure and/or study". ${ }^{14}$

Digitization of cultural heritage resources is also at the forefront of the 7th Framework Programme. EC has recently (24 August 2006) adopted a "Recommendation on the Digitisation and Online Accessibility of Cultural Material and Digital Preservation"15 in which Commission urges Member States to tackle three main areas: 1) Digitization of content by setting up large scale digitization facilities; 2) Online accessibility by promoting the development of the European Digital Library as the multilingual access point to Europe's cultural heritage; and 3) Digital preservation by establishing national strategies and plans for the long-term preservation of and access to digital material ${ }^{16}$.

Prepared as an annex to the EC's Communication "i2010: Digitial Libraries", a staff working document explains why the European Commission concentrates on the digitization of cultural heritage resources [10]. Members of Union spent more than 14 billion Euro for libraries, archives and museums as cultural heritage organizations. Content industries constitute 5\% of Europe's GDP. Cultural heritage institutions give more to library users and to the society in general than what they get as government funding. "Digitization of the content resources held by libraries, archives and museums, and making them available electronically could considerably increase their economic impact." ([10], p. 4).

The working document also discusses the financial, organizational, technical and legal challenges that need to be tackled to streamline the digitization process. Digitization is expensive: it costs about 8-12 Euro to digitize a book. Establishing a Europewide "digitize once, distribute widely" policy that will guide the digitization initiatives in EU countries is quite challenging. Making digital copies is not enough to create a European Digital Library. Technical issues such as interoperability between libraries, metadata creation and developing search technologies need to be resolved [10], p. 8). EU has spent some 50 million Euro between 2002 and 2005 for projects to tackle these issues (e.g., MINERVA ${ }^{17}$ ). The European Library Project covers 150 collections representing 11 million records and digitized objects and items ([10], p. 10).

The working document approaches the digitization of cultural heritage materials from two fronts: digitization of past materials (analog) and present materials (born-digital materials). The former is called "a future for the past" while the latter "a future for the present" ([10], p. 13-14). The challenges for the former are already mentioned above. Despite several ongoing digitization

\footnotetext{
11 http://www.archive.org/web/web.php.

12 http://www.alexa.com/site/company/technology.

13 See http://cordis.europa.eu/ist/ka3/digicult/.

14 http://europa.eu.int/information_society/activities/digital_libraries/index_en.htm.

15 http://ec.europa.eu/information_society/newsroom/cf/itemdetail.cfm?item_id=2782.

16 http://europa.eu.int/information_society/activities/digital_libraries/cultural/actions_on/policy_actions/index_en.htm.

17 For more information on MINERVA (Ministerial Network for Valorising Activities in Digitisation), see http://www.minervaeurope.org/.
} 
initiatives, it is estimated that only a small fraction (between $1 \%$ and $2 \%$ ) of total collections in EU libraries, archives and museums have been digitized so far ([10], p. 5). It is estimated that "the total cost of preserving the world's audio-visual archives by simple format transfer would be around 100 billion Euro" ([10], p. 14).

As part of the i2010 policy, EC funded the Europeana (www.europeana.eu) - Europe's digital library, museum and archive under the eContentplus programme. The Europeana aims to provide online access to the digital content of European museums, libraries, archives and audio-visual collections and involves 90 representatives of European heritage and knowledge institutions including 20 national libraries. The prototype website will be launched in November 2008 "giving users direct access to some 2 million digital objects, including film material, photos, paintings, sounds, maps, manuscripts, books, newspapers and archival papers" through a multilingual user interface. The number of digital objects available through the Europeana portal will reach 6 million by the year $2010 .^{18}$

\section{Conclusion}

"What we find changes who we become" [22]. The main issue is centred on where we look at first for what we search. We are increasingly turning to the Web in the flat world to look for information or services. What we look for may be as varied as ordering a pizza to eat, an MP3 file of a song to listen to, the full-text of a novel or the video of a movie that we wish to download from Amazon to read/view, or a 3D model of Michelangelo's David to view and to do research on. Services offered by Google may give an idea as to the wide range of searches that users perform on the Web (e.g., Google Scholar, Images, Groups, Maps, News, Video, Earth, Book Search, Blog Search, Answers, Froogle, Fight, and many others).

What we find in libraries and museums changes who we become, too. Yet, these repositories are no longer the first stops of users when searching for information, even though they may still offer the best and most authoritative resources and services. Almost 90\% of users consult search engines first. Users still stop by because the overwhelming majority of traditional sources such as books, local collections and cultural heritage resources are not on the Web yet and they can be found only in libraries and museums. But this might change soon. Library and museum resources and services need to be conveniently available on the network.

To conclude, then, in order for libraries and museums to become indispensable virtual destinations in the vast digital information landscape, they must move their resources and services to the network as quickly as possible and restructure themselves accordingly. They should strive to play an important role in users' increasingly networked work, learning, and living environments and compete with other web-based services. The issue of long-term preservation of digital information needs to be tackled. This appears to be the "sine qua non" of the survival of libraries and museums in the flat world.

\section{Acknowledgments}

I am grateful to Professor Mícheál Mac an Airchinnigh, Trinity College, University of Dublin, for his meticulous reading of an earlier draft of this paper, and thankfully acknowledge the comments of the two anonymous reviewers.

\section{References}

[1] Apps, A., \& MacIntyre, R. (2006). Why OpenURL? D-Lib Magazine, 12(5). (Online). Retrieved, 3 May 2008, from www.dlib.org/dlib/may06/apps/05apps.html

[2] Bergeron, B. (2002). Dark Ages II: When the digital data die. Upper Saddle River, N.J: Prentice Hall.

[3] Calhoun, K. (2006). The changing nature of the catalog and its integration with other discovery tools. (Final report prepared for the Library of Congress. March 17, 2006). Retrieved, 3 May 2008, from www.loc.gov/catdir/calhoun-report-final.pdf

[4] Clark, J. T., Slator, B. M., Perrizo, W., LandrumIII, J. E., Frovarp, R., Bergstrom, A., Ramaswamy, S., \& Jockcheck, W. (2002). Digital archive network for anthropology. Journal of Digital Information, 2 (4) \#107. (Online) Retrieved, 3 May 2008, from http://jodi.tamu.edu/Articles/v02/i04/Clark/

[5] De Groote, S. L., Hitchcock, K., \& McGowan, R. (2007). Trends in reference usage statistics in an health sciences library. Journal of the Medical Library Association, 95 (1), 23-30.

[6] Dempsey, L. (2005, July 5). The inside out library: libraries in the age of Amazoogle. (presentation slides). LIBER 34th Annual Conference: Pre-conference on 'Converging and Dissolving the University Library'. 5 July 2005. The Netherlands: University Library of Groningen (Online). Retrieved, 3 May 2008, from www. oclc.org/research/presentations/dempsey/liber.ppt

[7] Dempsey, L. (2005, October 19). The Library and the network: flattening the library and turning it inside out. (presentation slides). Access 2005 Conference, 19 October 2005. Edmonton, Alberta, Canada, (Online). Retrieved, 3 May 2008, from http://www.oclc.org/research/presentations/dempsey/edmonton.ppt

[8] Dempsey, L. (2006a, July). The library catalogue in the new discovery environment: Some thoughts. Ariadne, No. 48. (Online). Retrieved, 3 May 2008, from http://www.ariadne.ac.uk/issue48/dempsey/

[9] Dempsey, L. (2006b, February). The (digital) library environment: Ten years after. Ariadne, No. 46. (Online). Retrieved, 3 May 2008, from http://www.ariadne. ac.uk/issue46/dempsey/intro.html

[10] European Commission (2005). Staff working document. Annex to the Communication from the Commission "i2010: Digital Libraries." COM(2005) 465. Retrieved, 3 May 2008, from http://europa.eu.int/information_society/activities/digital_libraries/doc/communication/annex1_en.pdf

[11] Friedman, T. L. (2005). The world is flat: A brief history of the globalized world in the 21st century. London: Penguin Group.

[12] Hemminger, B., Bolas, G., \& Schiff, D. (2005). Capturing content for virtual museums: from pieces to exhibits. Journal of Digital Information, 6 (1) Article No. 313. (Online). Retrieved, 3 May 2008, from http://jodi.tamu.edu/Articles/v06/i01/Hemminger/

[13] IDC (2007, March). The expanding digital universe: a forecast of worldwide information growth through 2010. (An IDC white paper sponsored by EMC). (Online). Retrieved, 3 May 2008, from http://www.emc.com/collateral/analyst-reports/expanding-digital-idc-white-paper.pdf

[14] Kahle, B. (1997, March). Preserving the Internet. Scientific American, 276 (3), 82-83.

[15] Kohl, D. (2006). Where's the library? (Editorial). The Journal of Academic Librarianship, 32 (2), 117-118.

${ }^{18}$ Information in this paragraph comes from the Europeana website (http://www.europeana.eu). 
[16] Kuny, T. (1997). A Digital Dark Ages? Challenges in the presevation of electronic information. Paper presented at 63rd IFLA General Conference and Council Copenhagen, Denmark, 31 August - 5 September 1997. (Online). Retrieved, 3 May 2008, from http://www.ifla.org/IV/ifla63/63kuny1.pdf

[17] Kyrillidou, M., \& Young, M. (Eds.). (2005). ARL statistics 2003-04: A compilation of statistics from the one hundred and twenty three members of the Association of Research Libraries. Washington, D.C.: ARL. (Online). Retrieved, 3 May 2008, from http://www.arl.org/bm doc/arlstat04.pdf

[18] Kyrillidou, M., \& Young, M. (Eds.).(2004). ARL statistics 2002-03: A compilation of statistics from the one hundred and twenty three members of the Association of Research Libraries. Washington, D.C.: ARL. (Online). Retrieved, 3 May 2008, from http://www.arl.org/bm doc/arlstat03.pdf

[19] Lyman, P., \& Kahle, B. (1998 July/August). Archiving digital cultural artifacts: Organizing an agenda for action. D-Lib Magazine, 4 (Online). Retrieved, 3 May 2008, from http://www.dlib.org/dlib/july98/07lyman.html

[20] Lynch, C. (2002). Digital collections, digital libraries and the digitization of cultural heritage information. First Monday, 7 (5) (Online). Retrieved, 3 May 2008, from http://www.firstmonday.org/issues/issue7_5/lynch/

[21] Mac an Airchinnigh, M. (2004). Practical sense of philosophizing: Why preserve anything at all, even digitally? Review of the National Center for Digitization, 4,111-134 (Online). Retrieved, 3 May 2008, from http://www.ncd.matf.bg.ac.yu/casopis/04/d014/download.pdf

[22] Morville, P. (2005). Ambient findability. Sebastopol, CA: O'Reilly.

[23] NISO (2005). Z39.88-2004. The OpenURL Framework for Context-Sensitive Services. (Online) Retrieved, 9 September 2006, from www.niso.org/standards/ standard_detail.cfm?std_id=783

[24] OAI-PMH. (2006). Open Archives Initiative Protocol for Metadata Harvesting. (Online). Retrieved, 3 May 2008, from http://www.openarchives.org/OAI/ openarchivesprotocol.htm

[25] Preserving digital information. (1996). Report of the Task Force on Archiving of Digital Information commissioned by the Commission on Preservation and Access and the Research Libraries Group. (Online). Retrieved, 3 May 2008, from http://www.ifla.org/documents/libraries/net/tfadi-fr.pdf

[26] Rothenberg, J. (1995, January). Ensuring the longevity of digital documents. Scientific American, 272 (1), $42-47$ An expanded version of the paper is available online from http://www.kb.nl/hrd/dd/dd_links_en_publicaties/publicaties/dig-info-paper.rothenberg.pdf

[27] Rothenberg, J. (1999). Avoiding technological quicksand: Finding a viable technical foundation for digital preservation. Washington, D.C.: Council on Library and Information Resources (Online). Retrieved, 3 May 2008, from http://www.clir.org/PUBS/reports/rothenberg/contents.html

[28] Shreeves, S. L., Kaczmarek, J. S., \& Cole, T. W. (2003). Harvesting cultural heritage metadata using the OAI Protocol. Library Hi Tech, 21 (2), 159-169 (Online). Retrieved, 3 May 2008, from http://www.emeraldinsight.com/10.1108/07378830310479802

[29] Tonta, Y. (2006). Bilgi yönetiminde son gelişmeler: Amazoogle, işbirliği ve açık erişim. (Recent developments in information management: Amazoogle, cooperation and open access). (Presentation slides) Akademik Bilișim '06, 9-11 Şubat 2006, Denizli. (Online). Retrieved, 3 May 2008, from http://yunus. hacettepe.edu.tr/ tonta/yayinlar/tonta-ab-2006-bilgi-yonetiminde-son-gelişmeler.pdf.

[30] Tonta, Y. (2007). Libraries and museums in the flat world: Are they becoming virtual destinations? In Herbert K. Achleitner, \& Alexander Georgiev Dimchev (Eds.), Sofia 2006: Globalization, Digitization, Access, and Preservation of Cultural Heritage, 8-10 November 2006, Sofia, Bulgaria (pp. 92-105). Sofia: St. Kliment Ohridski, University of Sofia.

[31] Tonta, Y. (2007b). Kütüphaneler sanal güzergâhlara mı dönüșüyor? (Are libraries becoming virtual destinations?) In Ayşe Üstün \& Ümit Konya (Eds.) I. Uluslararası Bilgi Hizmetleri Sempozyumu: İletişim, 25-26 Mayıs 2006, İstanbul (Bildiriler) (pp. 353-366). İstanbul: Türk Kütüphaneciler Derneği İstanbul Şubesi.

[32] The University of California Libraries. Bibliographic Services Task Force (2005). Rethinking how we provide bibliographic services for the University of California. (Final Report. December 2005). Retrieved, 3 May 2008, from libraries.universityofcalifornia.edu/sopag/BSTF/Final.pdf.

[33] Van de Sompel, H., \& Beit-Arie, O. (2001). Open linking in the scholarly information environment using the OpenURL Framework. D-Lib Magazine, 7 (3) (Online). Retrieved, 3 May 2008, from www.dlib.org/dlib/march01/vandesompel/03vandesompel.html

[34] Zorich, D. M. (2003). A survey of digital cultural heritage initiatives and their sustainability concerns. Washington, D.C.: Council on Library and Information Resources (Online). Retrieved, 3 May 2008, from www.clir.org/pubs/reports/pub118/pub118.pdf 